\title{
UNA JOYA POCO CONOCIDA (O ELOGIO DE LA INTUICIÓN): LA COLONIA LUKIŠKĖS EN VILNIUS (1911-13)
}

\author{
Javier Ruiz (Dr. Arquitecto - Profesor titular DUyOT)
}

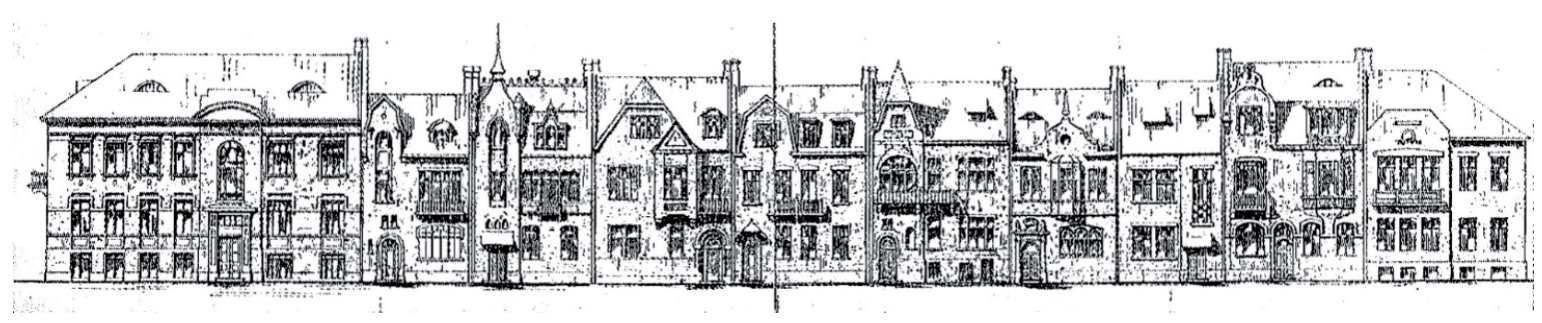

Este modesto texto no pretende ser más que un breve apunte, una reivindicación de una de esas pequeñas joyas urbanas apenas conocida y reconocida, generalmente debido a su condición periférica (lejanía geográfica o del centro del debate urbanístico imperante) o a su sólo aparente falta de pretensión culta, sobrepasada en cualquier caso por sus alcances y logros reales. También pretende, y de ahí el subtítulo "elogio de la intuición", servir de agradecimiento, y nada mejor que para ser incluido en el número con que se alcanza el primer centenar de Ci[ur], al marco que me ha permitido durante todos estos años entrenar la intuición que me permite, entre otras cosas, disfrutar del placer de la experiencia y la práctica del urbanismo. Porque mi descubrimiento de la pequeña joya que aquí presento se produjo, sin mayor expectativa previa, durante un solitario y distraído paseo por la capital lituana entre los dos hoteles que alojaban a los participantes en una conferencia.

La colonia Lukiškès ocupa una pequeña manzana triangular próxima al final de la Gedimino prospektas, la avenida más notable de la Vilnius moderna que parte de su centro histórico. Se trata de un conjunto formado por tres hileras de edificios adosados de manera que casi encierran un pequeño jardín común. Cada edificio ha sido proyectado de manera individualizada, algunos comparten patrones estilísticos en mayor o menor medida, otros presentan formas y funciones más singularizadas. Pese a una media de altura aproximadamente homogénea (tres alturas, a veces construcciones por encima de la cornisa, a veces semisótanos) el conjunto presenta una fascinante heterogeneidad, cabría pensar que más producto del tiempo (diversidad de fechas y autores, diversidad de programas y clientes) que de una voluntad más o menos unívoca.

La pequeña colonia es la mejor conservada de las promovidas por el financiero Juzef Montwill (Juozapas Montvila, en lituano) a principios del siglo XX, insertas en la doble tradición colonia obrera/ciudad jardín. El arquitecto del conjunto ( $y$ de la mayoría de los edificios) es August Klein, de origen germano, sólo algunos edificios proyectados por Wladislaw Stipulowski. Las instrucciones del promotor eran crear vivienda para clases medias y obreras, entremezcladas en un conjunto urbano con espacios libre compartidos. 

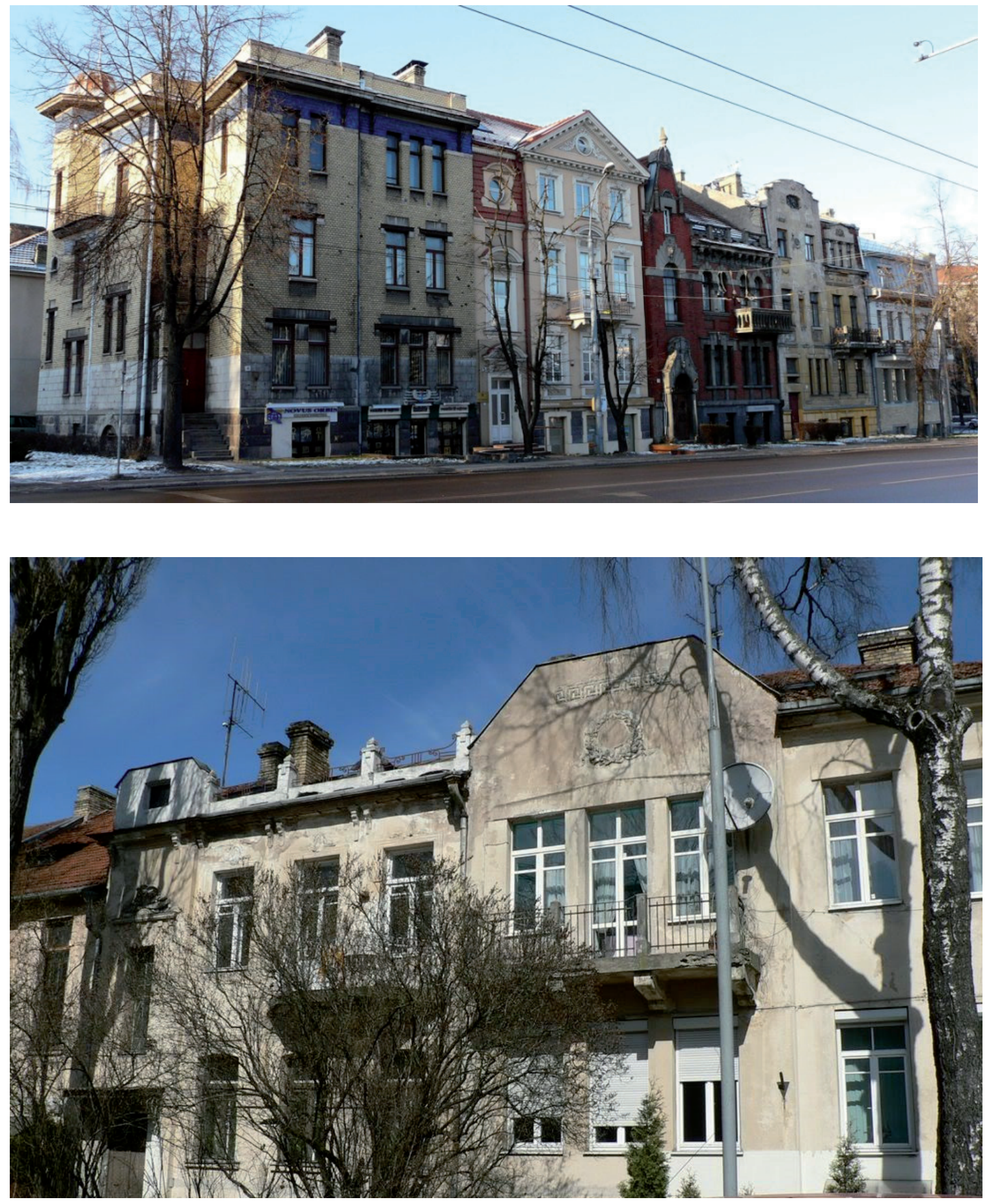

Figura 12. Dos vistas parciales de la colonia lukiškès Fuente: Archivo del autor 
Incluso las construcciones más singulares (el edificio en esquina proyectado por el arquitecto Waclaw Michniewicz para sí mismo) son coproyectadas o supervisado su diseño por Klein, de manera que se salvaguarda la armonía del conjunto en la diversidad pretendida.

Enfoscados rojos, blancos y terrosos, ladrillos vistos de color amarillo, toques de azulejo azul, o verde, cubiertas planas, frontones clásicos, formas románticas y modernistas, torreones, composiciones simétricas y muy complejas, modestia constructiva y ornamento pueden ser rastreados en cada uno de los edificios. El conjunto es, sin duda, magnífico, en su conjunto una lección de un cierto urbanismo que apuesta por la calidad urbana por encima de la rentabilidad económica y simplicidad proyectual/de gestión que por desgracia es ahora norma.

(Fotografías de Javier Ruiz y Silvia Fernández, a quien agradezco el paseo y la panorámica)
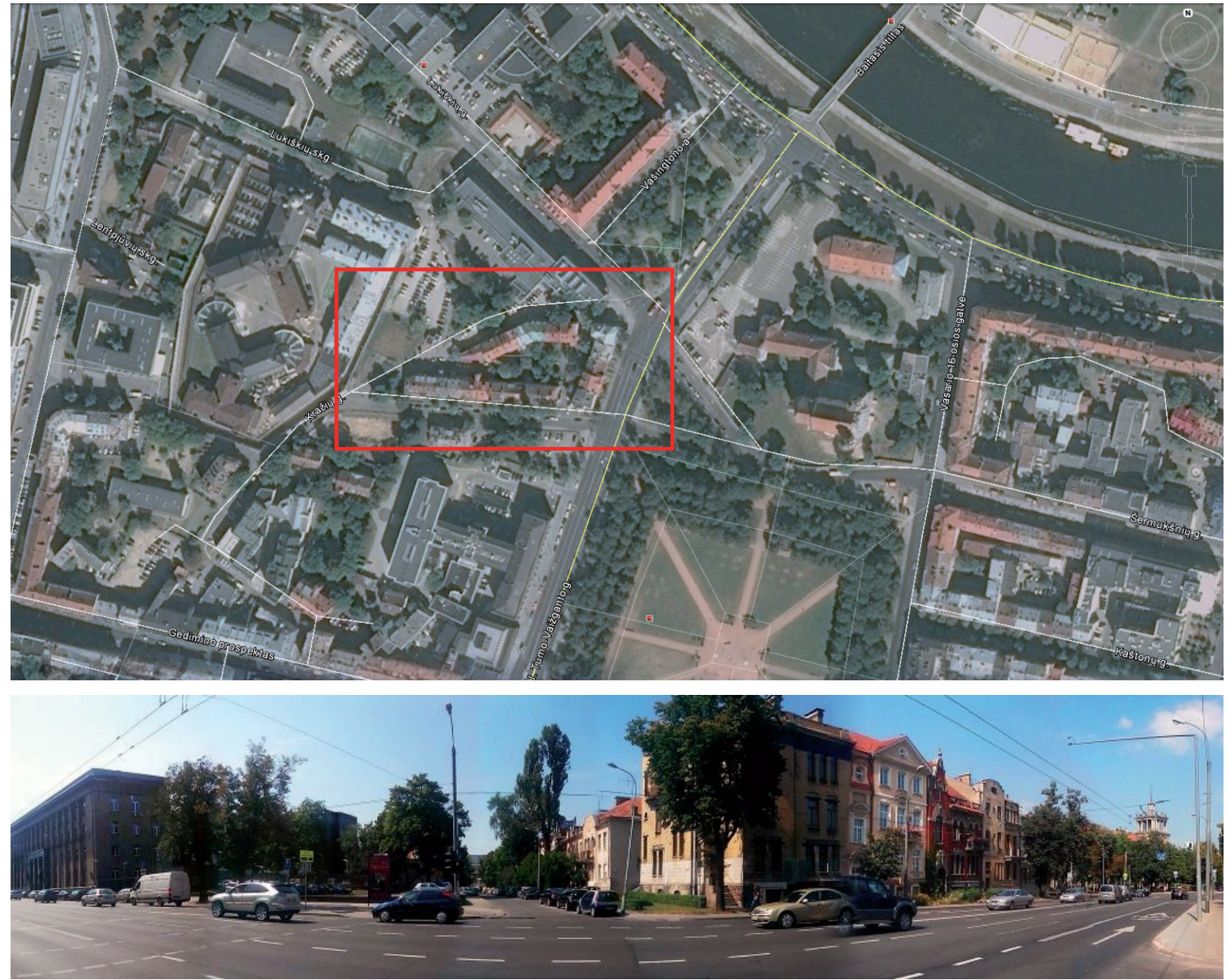

Figura 13. Planta y panorámica del conjunto Fuente: Google Earth y Archivo del autor 